\title{
The Current Situation of Engineering Graduates Cultivation in our University and the Countermeasure Research
}

\author{
Peng $\mathrm{LI}^{1, \mathrm{a}}$ \\ ${ }^{1}$ Northeast Dianli University No. 169 Changchun Road Jilin City, China \\ alip056@163.com
}

Keywords: Engineering postgraduate, Postgraduate education, Practice ability.

\begin{abstract}
As a comprehensive university mainly of engineering, cultivation of engineering graduate has always been the focus on graduate train. This article is based on our school engineering graduates cultivation realities, focusing on the problems and shortcomings analysis in the current training model, then propose solutions to this point, in order to further improve the level of our university graduates cultivation in engineering.
\end{abstract}

\section{Introduction}

China is on a fast track of social and economic development in recent years, especially in the field of manufacturing, which is booming at a soaring speed. It is an unavoidable trend for China to change its status, from a strong manufacturing country to a super manufacturing country, which is the very access to a real rich nation. Therefore, the threshold for talents in manufacturing filed is enhanced. It is hard to find a comprehensive student who has both innovation and practical abilities., hence training gradates of engineering becomes a big challenge for most universities. It is of vital importance for universalities to put emphasis on the construction of a reasonable mode to foster the graduates of engineering.

\section{Analysis on current situation of engineering graduates training}

\section{Theory study derails from practice}

From the graduate admission until graduation, theory study runs through the whole process of graduates training, which is a very important part for graduate learning. An innovative knowledge reserve cannot be obtained unless students have a solid theory foundation. However, we must realize in the mean time that theoretical teaching is not enough when it comes to graduate training. If we say theory is the seed, then practice is the fertile soil to foster it. It cannot harvest abundant fruit if the seed is not deep rooted into the soil of practice. A lack of practical abilities for our graduates is vividly reflected, which can be seen during the process of graduate training, i.e. theory study derails from practice. As we all know, the graduate entrance examination is mainly theoretical examination, which inevitably results in the students themselves taking the theory while neglecting practice. Most graduate students only "grind away at their studies and learn textbooks by rote" in order to pass the entrance examination. During the 2 years' study, most of the students focus on theory enhancement \& upgrading, wringing and rectifying papers. So there is hardly any practice opportunities for students. After graduation, those whom we considered to be outstanding have failed to fulfill their duties on their respective positions. It will take them plenty of time before adapting to the new working environment. This surely results from the imbalance between theory and practice during the process of graduate training.

\section{Hardware facilities is not perfect}

Now graduate admission is expanding annually whereas the construction of hardware facilities lags far behind. Experiment platform, a hardware foundation that can improve graduates' innovative and practical abilities, maintains at original level. Most of the graduates are admitted directly after finishing their undergraduate studies. They never have social practice. Experimental teaching is restricted by hardware facilities during the period of undergraduate study, all of which has hampered the graduates to form the abilities to innovate and practise. Though the situation is better during graduate study, it cannot 
meet the requirement to foster a competent graduate. This is largely reflected by the old experiment apparatus and the slow process of obtaining the miserable little advanced equipment. The R\&D platform cannot meet the requirement of experiment teaching and scientific research. This make it impossible for graduates to get a direct contact and understanding on the top-notched science and technology of its own field other than learning from the textbooks, which restrains the innovative abilities to a certain extent.

\section{Tutors' effects have been restricted}

As an important part of fostering a graduate, tutors' effect plays a vital role. The qualities and competence of a tutor go hand in hand with their students' scientific research. Moreover, the personal charisma will also influence graduates psychologically. There is no doubt that a well-educated strict tutor will have a profound influence on graduates' study and life. Currently the replacement of old and new is speeding up year by year. Excellent tutors have been promoted to an administrative post whereas newly-promoted tutors lack of the experience to manage graduates. This makes the already inadequate tutor resources becomes more stretched. Under the mechanism of double-way selection, it is not strange to find that some tutors have plenty of students to instruct while others have no students to teach. All of these add to the restraint of a tutor's effect and set a barrier for the training for a high level engineering graduate, which consequently is harmful to students' academic research and scientific practice.

\section{Training system is single}

At present, the training system of our school is relatively single, mainly based on tutors subject to carry out the related research work. The subjects from tutors are mainly vertical, i.e. communication between schools and scientific research institutes and related enterprises are scarce. Under such circumstance, the innovative and practical abilities of the graduates are highly restricted, which vividly reflects as the derailment of scientific research from social practice. Most of the scientific research achievements become empty talks and the conversion rate is very low.

\section{Countermeasure research on situation of current graduates' cultivation}

\section{To raise the awareness of the importance of practice, and further promote the integration of theory and practice}

First, we must recognize that practice training is as important as theory teaching. They are of the equivalent importance. Second, the ratio of practice training shall be increased during the process of graduates' cultivation. The practical abilities of engineering graduates shall be incorporated into the daily assessment work.. The detailed work is shown as below. (1) practical abilities shall be incorporated as a criterion during the interview of graduate admission, enhancing the awareness of the interviewees to attach importance to it.(2) the ratio of experimental classes shall be increased so as to enable the graduates to consolidate their knowledge during the experimental process, and consequently improve their practical abilities.(3) encourage graduates to "walk out" and actively participate in the activities in relation to their respective field so as to stimulate their enthusiasm towards practical activities. (4)hold practical abilities competition to improve their performance abilities and cultivate their innovation spirits. Those who stand out shall be praised and exemplified academically, enhancing the atmosphere of group participation in practical activities.

\section{Strengthen the construction of experiment platform and improve laboratory management}

The current experiment platform construction is on the normal track, but because the number of the students is too large and the funds are insufficient, the progress is slow; it needs further improvement of laboratory and experimental equipment management, making best use of the limited resources. The specific measures are as follows: (1) Relative experimental center shall be set up with limited funds to upgrade experiment teaching and scientific research (2)In order to obtain best results, the class time and the number of students shall be controlled reasonably with the limited experiment resources. (3)After class, the laboratory shall be open regularly and a teacher on duty shall answer the questions about the 
apparatus and facilities for the students so as to improve their practical abilities and cultivate their innovation spirits.

\section{Improve the instruction mode and maximize the effect of the tutors}

Because of limited tutor resources, our university applies the "one-to-many" instruction mode, which is quite popular among colleges and universities. Literally, a tutor instructs more than one student simultaneously. Under such circumstance, the tutor cannot fully perform the instruction, which in turn results in an immature development of the graduates. This has been reflected by the insufficient innovation abilities and weak practical abilities from the graduates. In order to improve this situation, relative measures must be taken to improve the instruction mode: from "single tutor" to "double tutors" or even tutors group step by step. Currently graduate study mainly takes double tutors mode. Tutor on campus is responsible for the theory instruction whereas tutor off campus put emphasis on engineering practice of the graduate. This has undoubtedly set a good example for the cultivation of an academic oriented graduate. After the double selection, 2 or 3 tutors with the same research direction can form a research group to instruct the graduates, which is beneficial to the knowledge expansion and innovation cultivation for the graduates.

\section{Set up production-education-research cultivation system}

To improve the current situation of our university graduate training situation, in the final analysis is to reform the traditional education system, the establishment of enterprise-university-research institutions accelerating the construction of joint postgraduate training base, condensation of regional talent, industry and scientific research advantage, and gradually form a system of compound talents that match industrial development and scientific progress, so that the graduates of knowledge structure and ability level matches enterprises and research institutions of higher demand, develop Engineering graduates who meet the needs of the current regional development [5].The detailed mode is as follows: (1) to establish the teaching practice base and simulate business environment. (2) to establish a base of enterprise engineering practice, let students commence in-depth study, taking enterprise project as background, improve their practical abilities and have a definite object in view. (3) the construction of scientific research in distance education network shall be set up, so that students can understand the dynamics of the subject through the network teaching mode at first hand, cultivation of innovative thinking, stimulate the interest of scientific research.

\section{Conclusion}

Postgraduate education is the highest level in the education system. A nation's postgraduate education quality directly affects its economic, cultural, technological and social development. Comprehensive talents of high quality and high level are in hot demand in society, which is precisely the current graduate education direction. For engineering graduate students, it is urgent to set up production-education-research cultivation system, upgrade the outdated tutor instruction mode so as to let students truly avail of what they have learnt into practice [6]. Currently education departments and colleges\&universities are in the continuous attempts and efforts to reinforce scientific research funds and carry out reforms on educational system. The scholarship system reform and the postgraduate training has a positive effect on institutional improvement and innovation. It is believed that through joint efforts, the cultivation of engineering graduates will be improved considerably and the qualities of the engineering graduates will reach a higher level as well.

\section{References}

[1] Zhou Meilan, Meng Dawei, Ge Baojun. A discovery on urgently needed talents in electrical engineering by production-education-research cultivation [J] Talents Cultivation Reform2013.6 (14): 15-19.

[2] Zeng Xingwen, Pei Qingqi. Practical aspects strengthening the cultivation of engineering graduates [J]. China higher education research, 2005 (1): 30-32. 
[3] Wu Zufang. The analysis and practice on the mode of engineering graduates cultivation under the new situation [J]. Modern educational technology, 2010 (20): 166-168.

[4] Shen Yuanyuan. Current situation analysis and discussion of engineering graduates cultivation [J]. Modern education science, 2008 (5): 140-142.

[5] Xi Menghao. Cultivation reform on application-oriented talents and the discovery of practice base construction [J]. Economist 2009 (10).

[6] Li Liming. The cultivation of practical abilities for college students is inseparable with enterprises. [J]modern enterprise education.2006 (17). 